INRA Prod. Anim., 2000, 13 (3) , 185-200
. -F. HOCQUETTE, I. ORTI GUES-MARTY, M. DAMON*, P. HERPIN*, Y. GEAY

INRA Uni té de Recherches

sur les Herbi vores,

Thei x, 63122 St-Genés-Champanelle

*INRA Uni té mi xte de Recherches sur le Veau et le Porc, 35590 Saint-Gilles

e-mail : hocquet@dermont.inra.fr

\section{Métabolisme énergétique des muscles squelettiques chez les animaux producteurs de viande}

\begin{abstract}
Les substrats énergétiques captés par le tissu musculaire sont utilisés pour le développement du muscle au cours de sa croissance et pour son activité contractile. Ils peuvent être également stockés sous forme de glycogène ou de triglycérides. Les teneurs en ces deux éléments déterminent certaines caractéristiques qualitatives de la viande.
\end{abstract}

\section{Résumé}

La musculature des animaux destinés à la production de viande représente de 35 à $60 \%$ de leur masse corporelle. Source importante

\footnotetext{
Le muscle est d'importance économique majeure chez les animaux producteurs de viande. Ses principales fonctions physiologiques sont la thermogenèse, la posture et l'activité physique de l'animal. Ces fonctions et la croissance du muscle ont des besoins spécifiques en énergie, entraînant parfois des compétitions pour l'utilisation des différents nutriments. Ces régulations métaboliques modifient les efficacités de production et d'utilisation de l'ATP, et certaines caractéristiques musculaires déterminantes pour les qualités de la viande. Par exemple, un métabolisme musculaire plus glycolytique est associé à une meilleure utilisation du glucose, à une plus grande sensibilité du muscle à l'insuline, à un développement accru du muscle, à une réduction de ses dépenses énergétiques, et à une augmentation de sa teneur en glycogène. L'amélioration de la croissance musculaire par la sélection génétique induit un métabolisme musculaire moins oxydatif avec, comme conséquence, moins de lipides intramusculaires. Une augmentation des apports énergétiques favorise les dépôts de protéines, de glycogène et de lipides intramusculaires. Toutefois, des apports excessifs induisent une résistance du muscle à l'insuline favorisant le développement des tissus adipeux de la carcasse. Le turnover des nutriments et leur répartition entre les voies anaboliques (lipogenèse, gly. cogenèse) ou cataboliques (glycolyse, lipolyse, oxy-dation) intramusculaires restent à préciser. L'activité physique des animaux et la lutte contre le froid modifient les caractéristiques musculaires en favorisant le métabolisme oxydatif. La question qui se pose aujourd'hui est donc : l'optimisation des efficacités de production et d'utilisation de l'ATP est-elle compatible avec l'amélioration des qualités de la viande, déterminées notamment par les taux de glycogène et de lipides intramusculaires ?
}

de protéines pour l'alimentation humaine, elle assure chez l'animal vivant le maintien de la posture et permet le déplacement. Mais elle est également un acteur essentiel du métabolisme, en particulier du métabolisme énergétique. En effet, les nutriments énergétiques sont soit directement oxydés dans les muscles pour la production d'énergie libre, soit stockés (figure 1) sous forme de glycogène (pour le glucose) dans les fibres musculaires ou sous forme de triglycérides (pour le glucose et les acides gras), essentiellement dans les adipocytes intramusculaires. A l'abattage, ces stocks de lipides ou de glycogène du muscle influencent fortement, respectivement, la flaveur et le $\mathrm{pH}$ ultime de la viande. Ce dernier affecte aussi la couleur, la capacité de rétention d'eau, la jutosité et la tendreté de la viande (Touraille 1994).

Le métabolisme énergétique musculaire est également déterminant pour plusieurs fonctions physiologiques importantes du muscle : la production de chaleur lors d'une lutte contre le froid et la contraction musculaire au cours de l'activité physique (figure 1). Ces différentes fonctions sont en compétition pour I'utilisation de l'énergie (ATP), rendant les mécanismes métaboliques complexes à étudier. 
Figure 1. Métabolisme énergétique musculaire en relation avec la physiologie du muscle.

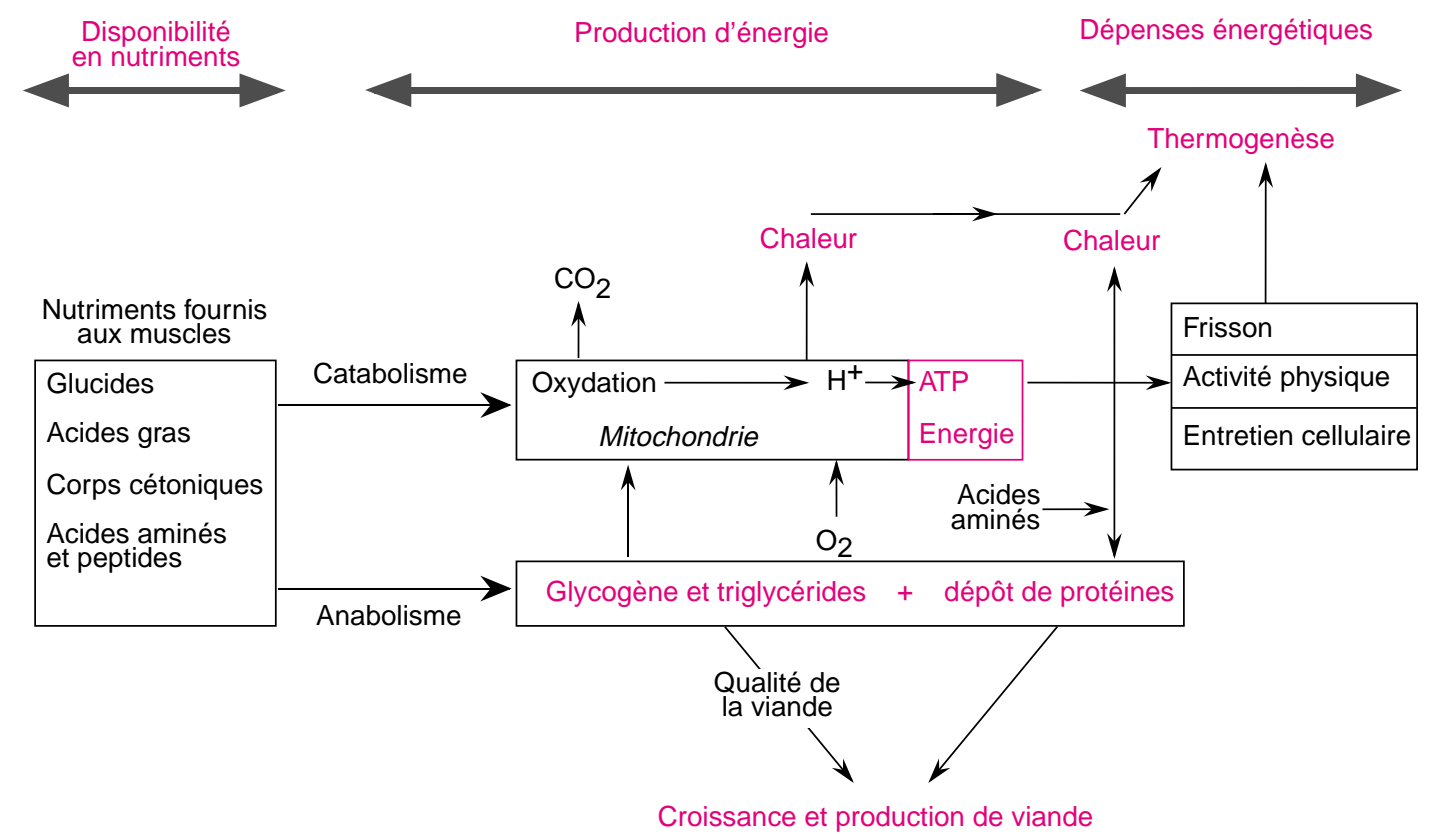

L'avancement des connaissances et le développement de nouvelles techniques d'investigation ont permis d'étudier spécifiquement le métabolisme de ce tissu chez les animaux en croissance dans un double objectif : d'une part, accroître le développement du muscle et maîtriser l'adiposité des carcasses afin de réduire les coûts de production et, d'autre part, améliorer les qualités organoleptiques de la viande afin de satisfaire le consommateur. C'est pourquoi des recherches ont été mises en place, chez les bovins, les porcins et les volailles, afin de maîtriser, par le biais de la nutrition, les caractéristiques musculaires qui déterminent les qualités organoleptiques des viandes. Ces recherches ont également pour objectif de maîtriser la part des nutriments énergétiques et azotés destinée aux principaux organes et tissus, afin d'accroître celle qui parvient au muscle.

L'objectif de cet article est donc de dresser, dans sa première moitié, un bilan des connaissances acquises au cours de ces dernières années sur les mécanismes mis en jeu, au sein du muscle, pour la production et la consommation d'énergie à partir des nutriments disponibles, en particulier au cours de la croissance, durant l'exercice physique ou la thermorégulation. La seconde partie est consacrée aux diverses possibilités de maîtrise du métabolisme énergétique, dans un sens favorable à la croissance musculaire et à l'amélioration des qualités de la viande.

\section{1 / Utilisation des nutriments et production d'énergie}

Le muscle squelettique est majoritairement composé d'eau et de protéines (environ 75 et $20 \%$, respectivement), les teneurs en lipides et glucides étant faibles ( 1 à $5 \%$ et 1 à $2 \%$ res- pectivement) (revues de Robelin et Casteilla 1990 et Lebret et al 1999). Le tissu musculaire est constitué de faisceaux de fibres enveloppées de tissu conjonctif riche en collagène, mais aussi d'adipocytes, et de cellules nerveuses, endothéliales ou sanguines. Les fibres sont des cellules musculaires plurinucléées constituées de faisceaux de myofibrilles. Entre les myofibrilles et à la périphérie des cellules musculaires, se trouvent respectivement les mitochondries intermyofibrillaires et subsarcolemmales (figure 2). Ces organites intracellulaires produisent une grande partie de l'énergie libre (ATP) nécessaire au muscle, à partir des substrats énergétiques apportés par la circulation sanguine (glucose, lactate, acides gras, triglycérides, corps cétoniques) ou endogènes (glycogène, triglycérides). Cette énergie est produite avec des rendements variables selon la local isation des mitochondries au sein de la cellule, la nature des nutriments énergétiques qui parviennent au muscle et le statut physiologique de l'animal (revues de Faergeman et Knudsen 1997 et Rolfe et Brand 1997).

\section{1 / Diversité métabolique des fibres musculaires}

Les principales voies du métabolisme énergétique musculaire sont classiquement caractérisées par la mesure des activités d'enzymes spécifiques. On peut ainsi grossièrement distinguer le métabolisme glycolytique (voies $A$ et $B$; figure 3 ) du métabolisme oxydatif (voies $C$ à $E$; figure 3 ) et classer ainsi les fibres ou les muscles en types glycolytique, oxydatif ou oxydo-glycolytique.

Les différentes voies métaboliques ne répondent pas de façon similaire aux différents facteurs de régulation. En effet, l'activité de certaines enzymes peut, dans certains cas, être insuffisante et limiter ainsi l'activité 
de toute une voie métabolique. Par ailleurs, un accroissement important des besoins en énergie du muscle peut accroître l'activité des étapes limitantes simultanément dans les voies glycolytique et oxydative (ceci a été observé dans le muscle masseter au moment du sevrage chez le veau ; Hocquette et al 1997).

En plus de leurs propriétés métaboliques les fibres musculaires se distinguent par leurs caractéristiques contractiles (contraction lente ou rapide). Les classifications qui en découlent considerent trois principaux types de fibres : les fibres lentes-oxydatives (de type I ou SO), les fibres rapides oxydo-glycolytiques (de type IIA ou FOG) et les fibres rapides glycolytiques (de type IIB ou $F G$ ). Toutefois, il n'existe pas de correspondance parfaite entre les propriétés contractiles et métaboliques des fibres musculaires. Une autre complication provient de l'hétérogénéité du métabolisme énergétique le long d'une seule fibre musculaire et, surtout, au sein d'un même muscle (revue de Hocquette et al 1998a). Néanmoins, sur la base de la mesure de certaines activités enzymatiques caractéristiques, il est possible, au sein d'une même espèce, de classer grossièrement les muscles du plus oxydatif au plus glycolytique. II est aussi possible de détecter d'importantes différences entre espèces selon l'activité oxydative moyenne de leurs muscles que l'on peut classer dans l'ordre décroissant suivant : mouton $>$ bovin $>$ porc $>$ volailles (revue de Hocquette et al 1998a). Il est intéressant de remarquer que cet ordre est le même que celui des teneurs moyennes des muscles en lipides (revue de Fauconneau 1997). Autrement dit, sur la base de comparaisons entre espèces, les muscles les plus oxydatifs contiennent le plus de lipides avec toutefois quelques exceptions comme le Bison, espèce aux muscles oxydatifs mais avec peu de lipides (Agabriel et al 1998). Cependant, les comparaisons au sein d'une même espèce n'ont pas permis d'établir de relation générale entre le caractère oxydatif d'un muscle et sa teneur en lipides. Ceci s'explique par le fait que les triglycérides contenus dans les fibres ne représentent qu'une faible proportion des triglycérides intramusculaires totaux dont la majorité est localisée dans les adipocytes intramusculaires (revues de Lebret et al 1999 et Mourot et al 1999).

\section{2 / Métabolisme des nutriments énergétiques dans le tissu musculaire}

L'apport des nutriments au muscle (glucose, acide gras, lactate, etc) par la circulation sanguine correspond au produit du débit sanguin par la concentration artérielle. Ainsi, la contribution des acides gras volatils (acétate) à la satisfaction des besoins du muscle en énergie est plus importante chez les ruminants que chez les monogastriques, simplement en raison de concentrations artérielles plus élevées chez les premiers.
Figure 2. Structure d'une fibre musculaire.

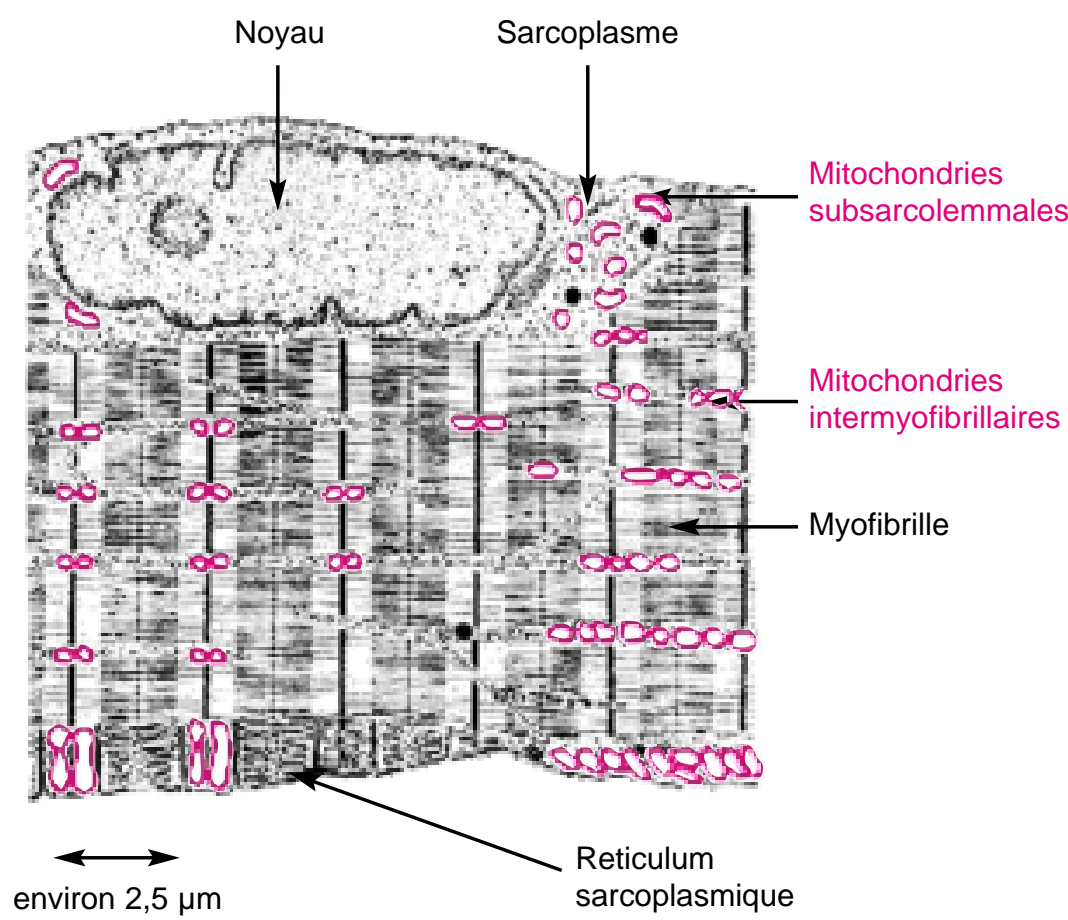

Une autre notion importante est la quantité de nutriments captée par le muscle. Celle-ci peut être mesurée in vi vo par la différence artério-veineuse de chacun des nutriments au niveau de la patte arrière (constituée principalement de muscles) pour les nutriments qui ne sont pas synthétisés de novo dans le muscle. Le taux de captage est très variable: de $4-9 \%$ pour le glucose à environ $40 \%$ pour l'acétate. Les résultats ainsi obtenus (apports et captage) permettent de calculer la contribution maximale potentielle de chaque nutriment énergétique au métabolisme du muscle. Néanmoins la contribution potentielle maximale du glucose au métabolisme musculaire est importante (de 30 à $60 \%$ ) aussi bien chez les monogastriques que chez les ruminants en raison d'un apport important au muscle qui compense largement sa faible efficacité de captage par les cellules musculaires (revues de Pethick 1984 et Ortigues et Visseiche 1995).

\section{a / Métabolisme du glucose}

Le captage du glucose est faible en raison de l'activité et de l'expression limitées des transporteurs du glucose présents dans les membranes des cellules musculaires et adipeuses (Hocquette et al 1996a). Dans le cas du muscle au repos, le glucose peut être métabolisé par différentes voies biochimiques : oxydation complète dans les mitochondries, recyclage sous forme de lactate, conversion en glycogène dans les fibres ou en lipides dans les adipocytes intramusculaires (figure 3). Chez le mouton, seulement 18 à 26 $\%$ du glucose capté est directement oxydé, le reste étant probablement stocké sous forme de glycogène avant d'être ultérieurement oxydé (Pethick 1984). 
Figure 3. Principales voies du métabolisme énergétique musculaire.

GLUT4 : isoforme 4 du transporteur du glucose, GS : glycogène synthase, Phos.: phosphorylase, PFK : phosphofructokinase, LDH : lactate déshydrogénase, LPL : lipoprotéine lipase, FABP : protéine de liaison des acides gras (forme cardiaque : $\mathrm{H}$, forme adipocytaire : A), CPT I : carnitine palmitoyltransférase I, CS : citrate synthase, ICDH : isocitrate déshydrogénase, $\mathrm{COX}$ : cytochrome $\mathrm{C}$ oxydase, ACX : acyl-CoA carboxylase, FAS : synthase des acides gras.

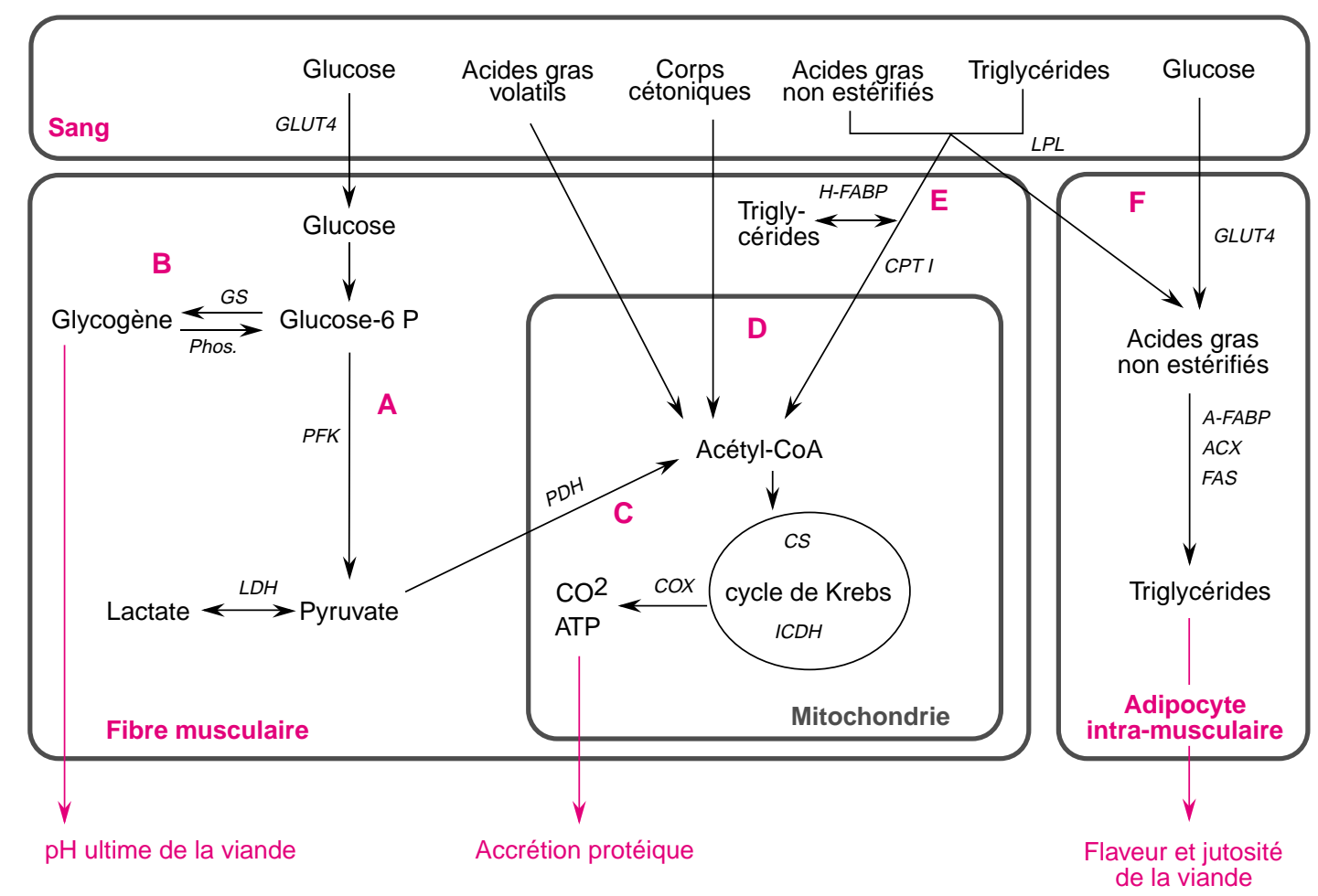

\section{Chez les ruminants, l'a cétate et les corps cétoniques contribuent pour plus d'un tiers au métabolisme oxydatif du muscle.}

\section{b / Métabolisme des lipides}

L'importance de la contribution de l'acétate et des corps cétoniques au métabolisme musculaire est une spécificité des ruminants, les acides gras volatils étant les principaux produits terminaux de la digestion des aliments chez ces espèces. Leur captage par le quartier arrière in vi vo est de l'ordre de $35-45 \%$ pour l'acétate et de 10-45 \% pour le ß-hydroxybutyrate et une forte proportion des quantites captées est complètement et directement oxydée. Ainsi, les contributions de l'acétate et des corps cétoniques au métabolisme oxydatif musculaire sont estimées à 15-40 \% et $18 \%$ respectivement chez les ruminants (revue de Pethick 1984).

Les acides gras à chaîne longue transportés par la circulation sanguine se trouvent soit sous forme de triglycérides, soit sous forme libre (ou non esterifiée). Les triglycérides sont un des constituants des lipoprotéines. L'hydrolyse par la lipoprotéine-lipase des triglycérides circulants en acides gras libres captés par les tissus sous-jacents, en particulier le muscle, est considérée comme une étape limitante pour I'utilisation des triglycérides à des fins énergétiques. Les concentrations artérielles des acides gras non estérifiés (AGNE) sont très différentes entre espèces (environ dix fois plus faibles chez le mouton que chez l'Homme) et varient en fonction des conditions physiologiques ou d'alimentation (augmentation lors de la mobilisation des réserves lipidiques du tissu adipeux par exemple en cas de jeûne, de sous-nutrition, d'exposition au froid ou d'exercice). Le taux de captage des AGNE par le muscle est de l'ordre de $20 \%$, mais seulement environ 3 à $40 \%$ des AGNE captés sont directement oxydés. La contribution maximum des AGNE au métabolisme oxydatif musculaire serait ainsi de l'ordre de $5 \%$ chez le mouton adulte contre 70-100\% chez I'Homme. Cette différence importante résulte essentiellement des différences d'apports d'acides gras longs aux muscles, bien plus élevés chez l'Homme que chez les ruminants (revues de Pethick 1984 et Pethick et Dunshea 1993).

A l'intérieur de la cellule musculaire (figure 3), les acides gras sont liés à des protéines de liaison spécifiques (FABP, pour Fatty Acid Binding Protein) qui transportent les acides gras vers les sites d'oxydation (peroxysomes, mitochondries) ou d'estérification (cytosol). Les peroxysomes sont de petits organites intracellulaires qui dégradent partiellement les acides gras à chaîne longue en acides gras à chaîne plus courte, pouvant aller jusqu'au stade acétyl-CoA. Les acides gras à chaîne longue ou courte sont ensuite transférés à l'intérieur des mitochondries où ils sont complètement catabolisés par les enzymes du cycle de Krebs. L'entrée des acides gras dans les mitochondries, sous le contrôle d'une enzyme spécifique, la carnitine palmitoyltransférase I (CPT I), est considérée comme l'étape limitante de l'oxydation mitochondriale des acides gras, que ce soit dans le foie ou dans les muscles (revue de Hocquette et Bauchart 1999). L'expression de cette enzyme 
et sa régulation font I'objet de nombreuses études, non seulement chez les rongeurs de laboratoire, mais, plus récemment, chez les espèces zootechniques comme le porcelet (Schmidt et Herpin 1998) et le veau (revue de Hocquette et Bauchart 1999).

\section{c / Interaction entre nutriments énergétiques}

Le cycle de Randle décrit la compétition entre l'oxydation des lipides et celle des glucides. E $n$ effet, le catabolisme des acides gras génère du NADH, de l'ATP et de l'acétyl-CoA qui inhibent la principale enzyme de l'oxydation du glucose, la pyruvate deshydrogénase (figure 4). Ainsi, une infusion in vivo d'acétate épargne le glucose comme source d'énergie. Réciproquement, plusieurs auteurs ont montré récemment qu'une stimulation du catabolisme du glucose diminue l'oxydation des acides gras via l'inhibition de la CPTI par le malonyl-CoA (Sidossis et Wolfe 1996) L'importance de ces phénomènes interactifs dépendra fortement de l'importance de la demande en énergie et de l'état physiologique des animaux (adaptation ou stress froid, intensité et durée de l'exercice avec ou sans entraînement, animal en croissance ou à l'entretien).

\section{3 / Dépenses énergétiques du muscle et consommation d'oxygène}

\section{a / Dépenses énergétiques in vivo}

Les données disponibles sont trop peu nombreuses et trop variables pour mettre en évidence des différences d'activité métabolique entre espèces de taille distincte (revue de Hocquette et al 1998a). Cependant, à taille équivalente des animaux, l'activité métabolique musculaire est fortement influencée par le niveau moyen d'activité physique et de nombreux autres facteurs (statut hormonal, type de fibres, température ambiante). Par exemple, chez le mouton couché ou debout, l'activité métabolique du quartier arrière est respectivement de 103 ou $138 \mathrm{~kJ}$ par jour et par $\mathrm{kg}$ de poids vif (Ortigues et Vermorel 1996). Cet exemple souligne la contribution importante de la station debout aux dépenses énergétiques journalières du muscle (environ $30 \%$ chez les ruminants ; Lobley 1991).

Bien que le muscle représente une part importante du poids corporel, la contribution de la masse musculaire aux dépenses énergétiques totales de l'organisme n'est que 12 à 20 $\%$ chez les ruminants (Ortigues 1991), $27 \%$ chez les oiseaux (Duchamp et Barré 1993) et 30 à $50 \%$ chez le porcelet (Lossec et al 1998), contre près de $50 \%$ pour l'ensemble des tissus splanchniques (tube digestif et foie). Ces faibles contributions, en particulier chez les animaux les plus grands, s'expliquent par la faible activité métabolique specifique du muscle comparativement à celle du foie ou du tube digestif (revue de Ortigues et Doreau 1995).
Figure 4. Fonctionnement d'une mitochondrie. PDH : pyruvate déshydrogénase, CPT I : carnitine palmitoyltransférase I, COX : cytochrome c oxydase, UCP: protéine découplante, ANT : adenine nucleotide translocase, ATP Synt. : ATP Synthase. Le catabolisme des substrats énergétiques génère un gradient de protons entre les deux membranes mitochondriales. L'énergie des protons est soit convertie en ATP soit diffusée sous forme de chaleur quand ces protons retournent dans la matrice mitochondriale via les UCP.

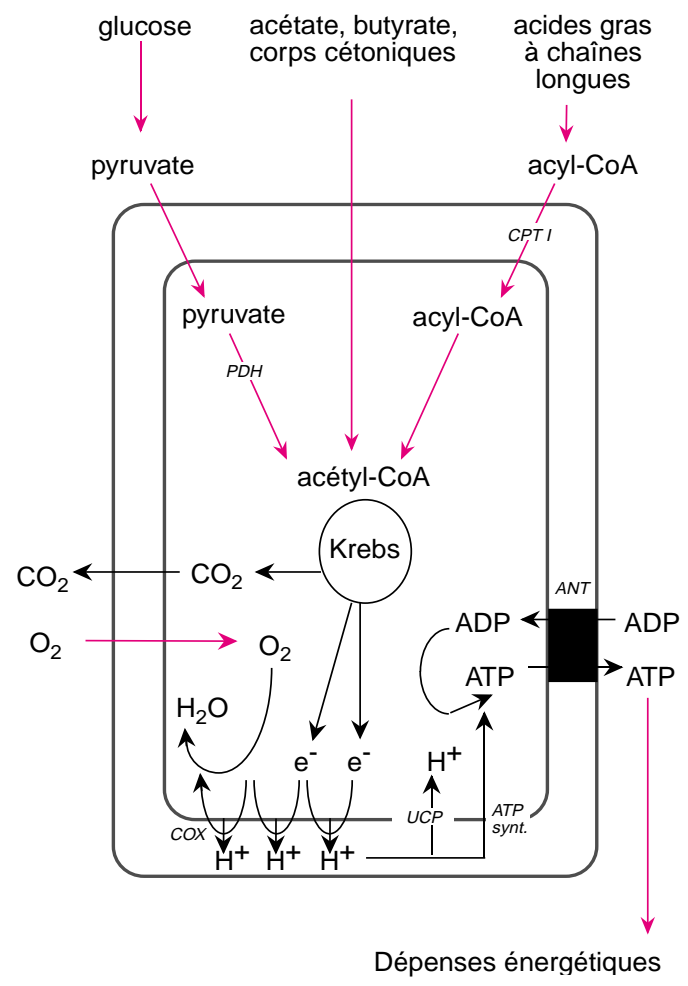

\section{b / Transport de l'oxygène aux muscles}

La satisfaction des besoins en oxygène du muscle dépend du flux sanguin, de la pression partielle en oxygène du sang artériel, du captage de l'oxygène par le muscle et des teneurs musculaires en myoglobine (qui fixe l'oxygène) et en mitochondries (sites d'utilisation de l'oxygène).

En cas d'exercice ou d'exposition au froid, l'augmentation des besoins en oxygène du muscle est associée dans un premier temps à une augmentation du flux sanguin (revue de Elia 1995). Dans le cas du muscle au repos, d'autres mécanismes de régulation peuvent intervenir, comme par exemple une variation du captage par le muscle ou une modification de la répartition du flux sanguin entre capillaires de petit ou de grand diamètre, modifiant ainsi la surface d'échange entre le sang et les cellules tissulaires (revue de Lobley 1994). Par ailleurs, le transport de l'oxygène dépend également de la teneur sanguine en hémoglobine, celle-ci étant variable selon les espèces. La capacité des muscles à utiliser l'oxygène est proportionnelle à leur teneur en mitochondries. Cette dernière est plus élevée chez les espèces de petite taille que chez les espèces de grande taille, plus élevée dans les 
muscles des espèces actives ou très mobiles (chien, cheval) que dans ceux des espèces calmes ou sédentaires (chèvre, bovin), et plus importante dans les muscles oxydatifs que glycolytiques (revue de Hocquette et al 1998a).

\section{c / Oxydation intracellulaire des nutriments}

L'énergie générée par le catabolisme des substrats énergétiques est soit convertie en ATP (figures 1 et 4 ), soit diffusée sous forme de chaleur, permettant ainsi à l'animal de maintenir sa température corporelle.

Plus précisément, l'oxydation des nutriments au sein des mitochondries conduit à une expulsion de protons de la matrice vers l'espace intermembranaire (figure 4). Ces protons vont se concentrer entre les deux membranes mitochondriales et générer une différence de potentiel électrochimique qui permet la synthèse de l'ATP par l'ATP synthase lors du retour des protons dans la mitochondrie : on dit alors qu'il y a couplage entre oxydation des nutriments et synthèse d'ATP (figure 4). Mais les protons peuvent emprunter d'autres voies pour traverser la membrane interne, et notamment être transportés par des protéines membranaires récemment découvertes, les protéines découplantes (UCP, pour uncoupling protein). Dans ce cas, le fonctionnement de l'ATP synthase est en partie court-circuité et la synthèse d'ATP diminue (figure 4).

L'efficacité de la synthèse d'ATP peut ainsi être modulée. Un défaut de couplage dans les mitochondries entre le catabolisme des substrats et la production d'ATP correspond à une augmentation de la proportion d'énergie perdue sous forme de chaleur, ce qui peut être favorable à l'animal qui doit lutter contre le froid (revue de Hocquette et al 1998a). Inversement, une augmentation de l'efficacité de la production d'ATP à partir des glucides et des lipides induit un accroissement de l'énergie disponible notamment pour la contraction musculaire (activité physique, frisson) ou le dépôt de protéines chez l'animal en croissance.

\section{d / Rôle des protéines découplantes dans le contrôle du métabolisme}

En participant au contrôle de l'efficacité de la synthèse de l'ATP, les protéines découplantes jouent un rôle important dans la disponibilité en énergie dans le muscle (figure 4). Elles sont issues d'une famille de gènes initialement mise en évidence dans le tissu adipeux brun. Le rôle thermogène de l'UCP1 (première séquence clonée et spécifique du tissu adipeux brun) est clairement établi (Boss et al 1998). Plus récemment, la découverte de trois nouveaux gènes possédant une forte homologie avec le gène codant pour I'UCP1 et s'exprimant dans de nombreux autres tissus (UCP 2, protéine ubiquitaire et UCP3, UCP4 spécifiques respectivement du tissu musculaire et du cerveau) a renforcé l'intérêt pour ces protéines (Boss et al 1998). En effet, de par leur activité découplante, elles participent aux fuites de protons qui contribuent pour une large part au métabolisme basal de l'animal ( $25 \%$ chez le rat) ou des tissus ( $50 \%$ dans le muscle et $26 \%$ dans le foie; Rolfe et Brown 1997). Toutefois, les mécanismes mis en jeu sont encore mal connus et le rôle physiologique de ces protéines demeure hypothétique (revues de Boss et al 1998, Freake 1998, Ricquier et Bouillaud 2000).

La régulation hormonale et nutritionnelle de l'expression des gènes codant pour les UCPs diffère selon le type d'UCP et le tissu. Ceci suggère l'existence de fonctions spécifiques pour chacune des UCPs et un contrôle complexe de la balance énergétique de l'organisme. Actuellement, les données bibliographiques ne sont encore que partielles et ne concernent que l'Homme et les rongeurs. Toutefois, il apparaît que l'expression des gènes des UCPS dans le muscle et le tissu adipeux est fortement corrélée avec l'utilisation des lipides et des glucides, et modulée par plusieurs facteurs de variation du métabolisme énergétique de nature hormonale (triiodothyronine) ou physiologique (jeûne, activité physique). Au plan agronomique, l'enjeu est d'importance car ces protéines, qui viennent d'être mises en évidence chez le porc (Damon et al 2000), pourraient en partie expliquer les différences d'efficacité du métabolisme énergétique et d'adiposité des animaux, et donc intervenir dans la régulation de la croissance et des caractéristiques qualitatives des tissus.

\section{4 / Métabolisme énergétique du muscle au cours de l'activité physique}

L'activité physique augmente les dépenses énergétiques du muscle et modifie les caractéristiques musculaires. Toutefois, il est important de distinguer les effets directs d'un exercice aigu des effets chroniques induits par l'entraînement physique.

\section{a / Méta bolisme des glucides et des lipides durant l'exercice}

Pour couvrir l'accroissement de ses besoins énergétiques durant l'exercice, le muscle accroît l'oxydation du glucose et des acides gras. La fourniture de glucose au muscle est alors accrue suite à des modifications du métabolisme hépatique. Toutefois, durant l'exercice, le muscle utilise davantage les lipides que les glucides, de sorte que la contribution relative du glucose au métabolisme musculaire a tendance à diminuer (figure 5). En effet, une augmentation de l'intensité ou de la durée de l'exercice est associée à une mobilisation des réserves adipeuses et, de ce fait, à une forte augmentation des concentrations artérielles d'AGNE et de l'oxydation des lipides par le muscle (Harman 1991).

Les lipides produisent davantage d'énergie par molécule que le glucose, mais l'oxydation des lipides nécessite une consommation d'oxygène plus élevée que l'oxydation complète du glucose : 147 ATP sont produits et 26 molécules d'oxygène sont consommées par 
molécule d'acide stéarique contre 38 molécules d'ATP et 6 molécules d'oxygène par molécule de glucose. Cependant, par unité de temps, la quantité d'ATP produite est bien plus importante à partir de glucose qu'à partir de lipides (revues de Sahlin 1986, J eukendrup et al 1998).

Lorsque I'utilisation des glucides par le muscle devient trop importante, le glucose est converti en lactate par la voie de la glycolyse anaérobie. L'exercice au-dessus de ce seuil anaérobique est potentiellement limité par les réserves en glycogène du foie et des muscles (cas de l'exercice d'endurance) ou par l'accumulation d'acide lactique (cas du sprint).

Figure 5. Contribution potentielle maximum des métabolites énergétiques à l'activité oxydative du tissu musculaire in vivo chez le mouton (adapté de Pethick 1984 et Harman 1991).

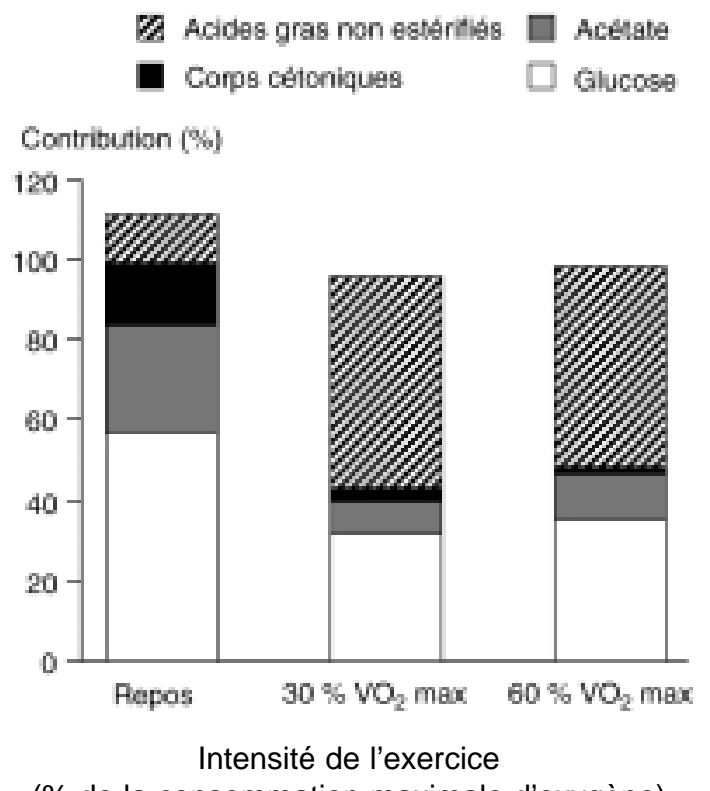

(\% de la consommation maximale d'oxygène)

\section{b / Conséquences de l'activité physique sur les caractéristiques des carcasses et des muscles}

Les muscles des espèces actives sont plus oxydatifs que ceux des espèces sédentaires, et utilisent davantage de lipides en situation d'exercice (revue de Henriksson 1995). Au sein d'une espèce comme le porc, un exercice physique quotidien augmente la capacité oxydative des muscles directement sollicités par l'exercice (revue de Lebret et al 1999). De même, la plus grande activité physique spontanée des bovins dans les stabulations libres par rapport aux stabulations entravées réduit l'activité glycolytique des muscles impliqués dans le mouvement (J urie et al 1998).

A même niveau alimentaire, l'augmentation du potentiel oxydatif des muscles induit par l'activité physique s'accompagne d'une réduction de la quantité de lipides stockée. Ainsi l'exercice régulier diminue le poids des carcasses chez le mouton, principalement en raison d'une réduction de la masse adipeuse (Pethick et Rowe 1996). De même, la masse adipeuse de la carcasse et des abats est plus faible chez les bovins en stabulation libre que chez ceux en stabulation entravée, à même niveau alimentaire (Jurie et al 1998). Les effets de l'exercice sur les teneurs en lipides intramusculaires sont beaucoup plus controversés (revue de Henriksson 1995), voire inexistants (revue Lebret et al 1999). En effet, au moins chez l'Homme, les individus entraînés ont moins de lipides dans les adipocytes intramusculaires, mais plus de lipides dans le cytosol des fibres musculaires (Hoppeler 1986) de sorte que l'effet global sur la teneur du muscle en lipides est probablement faible.

De plus, I'utilisation accrue des lipides pendant l'exercice permet une épargne du glycogène musculaire (revue de Henriksson 1995). Ainsi, quelle que soit l'espèce animale (porc: Essen-Gustavsson et al 1988, mouton : Pethick et Rowe 1996), le taux de glycogène intramusculaire a tendance à être augmenté par l'activité physique, ce qui explique probablement pourquoi le $\mathrm{pH}$ ultime de la viande peut parfois être plus faible chez le porc soumis a une activité physique contrôlée ou spontanée (revue de Lebret et al 1999). Cette augmentation s'explique au moins en partie par un accroissement de la sensibilité des muscles à l'insuline induit par l'activité physique (revue de Henriksson 1995). Une modification des taux circulants de glucose et d'insuline suggère effectivement que les muscles des bovins au pâturage sont plus sensibles à l'insuline que ceux des bovins alimentés à l'auge (Aoki et al 1995).

Tous ces effets dépendent, bien entendu, de la nature, de l'amplitude et de la durée de l'exercice physique auquel sont soumis les animaux. C'est la raison pour laquelle les différences de qualité de la viande entre systèmes d'élevage qui diffèrent par l'importance de la surface disponible par animal sont d'amplitudes très variables (revue de Lebret et al 1999).

\section{5 / Métabolisme énergétique du muscle et thermorégulation}

\section{a / Le rôle thermogène du muscle dans l'acclimatation au froid}

La thermorégulation contrôle l'équilibre entre les pertes (thermolyse) et la production (thermogenèse) de chaleur. Les mécanismes de la thermogenèse au froid sont classiquement regroupés en deux groupes: le frisson thermique et la thermogenèse sans frisson, celle-ci regroupant les mécanismes de production de chaleur n'impliquant pas de contractions musculaires (figure 1). Le muscle est le seul site du frisson et le tissu adipeux brun l'effecteur principal de la thermogenèse sans frisson. Toutefois, lors d'une acclimatation au froid, chez des espèces dépourvues de tissu adipeux brun (porc, oiseaux), une thermogenèse sans frisson peut apparaître dans le muscle et contribuer, avec le frisson thermique, à une consommation d'énergie affectant la croissance et certaines caractéristiques musculaires impliquées dans la qualité de la viande.

\section{L'activité physique augmente le poten- tiel oxydatif et la sensibilité des muscles à l'insuline.}




\section{b / Le frisson thermique}

Le frisson thermique résulte de contractions involontaires, rythmiques et simultanées de muscles squelettiques antagonistes. II n'induit pas de mouvement volontaire ou de travail extérieur, mais produit de la chaleur. Les mécanismes biochimiques intervenant au cours du frisson dépendent avant tout de la nature des fibres musculaires et des mécanismes impliqués dans la synthèse et l'hydrolyse de l'ATP (figure 4). L'efficacité thermogène du frisson est donc susceptible de varier: elle augmente avec l'âge chez le porcelet et au cours de l'acclimatation au froid chez les oiseaux (revue de Hocquette et al 1998a).

Tous les substrats énergétiques peuvent être utilisés par le muscle au cours du frisson, la sélection de ces substrats dépendant à la fois de l'intensité et de la durée de l'exposition au froid, et du statut physiologique de l'animal. Le porcelet nouveau-né est un modèle privilégie pour étudier ces mécanismes puisqu'il dépend quasi exclusivement du frisson pour produire de la chaleur lorsqu'il est exposé au froid. Ainsi, à cinq jours de vie, le captage du glucose par les muscles squelettiques augmente immédiatement après le début de l'exposition au froid du porcelet, alors qu'il faut attendre une heure avant que le même phénomène ne se produise pour les acides gras (Lossec et al 1998). Par ailleurs, lorsque l'exposition au froid est prolongée pendant 48 heures, on observe une augmentation des capacités respiratoires, oxydatives et de phosphorylation des mitochondries musculaires (Berthon et al 1996). Ceci doit probablement permettre d'approvisionner le muscle en énergie pour qu'il frissonne avec des quantités non limitantes d'ATP.

\section{c / La thermogenèse sans frisson}

Pendant une exposition prolongée au froid, le frisson est progressivement remplacé par la thermogenèse sans frisson, non seulement dans le tissu adipeux brun, mais aussi dans les muscles. Divers mécanismes thermogènes pouvant être impliqués dans la thermogenèse sans frisson ont été décrits dans le muscle.

En tout premier lieu, les fuites de protons au niveau de la membrane interne des mitochondries peuvent entraîner une baisse de la synthèse d'ATP (figures 1 et 4). En cas d'adaptation au froid, ce processus adaptatif peut s'intensifier (revue de Hocquette et al 1998a), mais ses bases moléculaires restent encore largement inconnues, même si les UCPS paraissent être de bons candidats.

D'autres aspects du fonctionnement mitochondrial tels que le transport du calcium, les échanges ATP/ADP (figure 4) et l'effet découplant des acides gras sont probablement impliqués dans ces modifications adaptatives de l'efficacité de la synthèse d'ATP (revue de Hocquette et Bauchart 1999). Par ailleurs, les transports actifs transmembranaires de $\mathrm{Na}^{+}$ et $\mathrm{K}^{+}$permettant le maintien de l'homéostasie ionique contribuent aussi significativement à la consommation d'oxygène et aux dépenses énergétiques cellulaires. (Herpin et al 1987). INRA Productions Ani males, jui llet 2000
Ces transports sont sous le contrôle des hormones thyroïdiennes, de la noradrénaline et du glucagon (revue de Clausen 1986).

Enfin, un accroissement du flux sanguin total, du nombre et de la nature des capillaires perfusés, sous l'effet d'agents vasoconstricteurs tels que la noradrénaline et la sérotonine, peuvent aussi participer à la thermogenèse sans frisson (Newman et al 1996).

\section{d / Conséquences d'une exposition au froid sur les caractéristiques du muscle et de la carcasse}

Peu d'études ont abordé cet aspect et elles n'ont concerné que les monogastriques. Une exposition chronique de trois semaines au froid s'accompagne d'une augmentation du métabolisme oxydatif du muscle chez le porcelet (Herpin et Lefaucheur 1992). Lorsque l'exposition au froid est prolongée jusqu'au poids habituel d'abattage, les mêmes effets sont obtenus : le métabolisme du muscle semi spinalis (muscle rouge) est plus oxydatif, sa teneur en lipides est plus importante et son potentiel glycolytique (une estimation de la teneur en glycogène) est réduit par rapport au muscle maintenu à la neutralité thermique, alors que ce potentiel augmente dans le muscle longi ssi mus thoracis (muscle blanc) (Lefaucheur et al 1991). Chez le canard, l'exposition au froid induit une augmentation du métabolisme oxydatif à la fois dans les parties rouges et blanches du muscle gastrocnémien (Duchamp et al 1992).

Les relations entre ces modifications biochimiques induites par l'exposition au froid et la qualité de la viande restent, en revanche, à préciser. Par exemple, chez le porc, l'exposition au froid pourrait avoir des effets sur le $\mathrm{pH}$ ultime de la viande dans les muscles blancs, compte tenu de la modification du potentiel glycolytique, et sur la flaveur puisque le contenu en lipides est plus élevé dans les muscles rouges. L'exposition au froid s'accompagne aussi d'une diminution de la capacite de rétention d'eau des muscles rouges et d'une proportion plus importante d'acides gras insaturés conduisant à un gras plus mou et plus oxydable. Toutefois, tous ces effets sont variables en fonction de l'importance de la diminution de la température ambiante (revue de Lebret et al 1999).

\section{2 / Mise en place et contrôle du métabolisme énergétique du muscle au cours de la croissance}

Les paragraphes précédents ont précisé les mécanismes mis en jeu au sein du tissu musculaire pour générer, à partir des divers nutriments, l'énergie libre nécessaire à ce tissu. Sur la base de ces connaissances, des recherches sont en cours pour maîtriser le métabolisme musculaire, qui varie tout au long de la vie de l'animal et qui est sous le contrôle de divers facteurs génétiques, nutritionnels et hormonaux. 


\section{1 / Intérêt de la maîtrise du métabolisme énergétique musculaire}

Pour les animaux producteurs de viande l'objectif principal de la maîtrise du métabolisme énergétique musculaire consiste à favoriser le dépôt de protéines et, par suite, la croissance, tout en optimisant certaines caractéristiques musculaires impliquées dans le déterminisme de la qualité de la viande (teneurs en lipides et en glycogène par exemple) (figure 6).

\section{a / Augmenter ou maintenir le nivea u de dépôt de protéines}

Dans la cellule musculaire, l'énergie libre (ATP) est requise aussi bien pour la synthèse que pour la dégradation des protéines. En conséquence, toute variation de la quantité d'énergie disponible peut altérer le dépôt de protéines et, inversement, tout changement dans le turn-over protéique peut induire des changements dans les besoins énergétiques du muscle.

Ainsi, au niveau cellulaire, une corrélation positive a été mise en évidence in vi tro entre le taux de synthèse protéique et la teneur du muscle en ATP (Hedden et Buse 1982, MacLennan et Rennie 1989). Pour I'animal entier, un accroissement de l'énergie ingérée augmente davantage le taux de synthèse protéique que le taux de dégradation des protéines. Par ailleurs, le coût énergétique d'un gramme de protéines déposées est probablement plus important dans les muscles lents oxydatifs, car les intensités de synthèse et de dégradation des protéines (c'est-à-dire le turn-over des protéines) y sont plus importantes que dans les muscles glycolytiques rapides.
A côté de ces aspects strictement quantitatifs, il est nécessaire de préciser que la nature des nutriments énergétiques est également importante pour la régulation du métabolisme protéique. Ainsi, par exemple, le glucose induit une stimulation de la synthèse des protéines et une inhibition de leur dégradation dans le muscle de rat incubé in vitro alors que les effets d'autres nutriments énergétiques (pyruvate, ß-hydroxybutyrate) sont moins importants (revue de Hocquette et al 1998a). In vivo, des apports de glucose conduisent généralement à une réduction des pertes d'azote contrairement à des apports de lipides (revue de Young et al 1992).

\section{b / Améliorer les qualités de la viande}

Après l'abattage, l'activité métabolique résiduelle du muscle conduit à la conversion du glycogène en acide lactique. La vitesse de chute du pH dépend de la vitesse de contraction des fibres musculaires (revue de Klont et al 1998), alors que la valeur du pH ultime de la viande dépend de la teneur en glycogène du muscle (revue de Sellier et Monin 1994). L'évolution du pH post-mortem influence principalement la couleur, la capacité de rétention d'eau, la jutosité et la tendreté de la viande (figure 6). La teneur en glycogène des muscles au moment de l'abattage dépend en partie des échanges préalables des substrats énergétiques entre le foie, le tissu adipeux et les muscles (Lister et Spencer 1983, revue de Hocquette et al 1998b). C'est ainsi que le stress ou l'activité physique musculaire avant abattage peuvent affecter la qualité de la viande en modifiant la teneur en glycogène.

Le métabolisme oxydatif du tissu musculaire intervient également dans le déterminisme de certaines caractéristiques de la viande, en particulier sa couleur, sa jutosité et sa flaveur

Figure 6. Relations entre le métabolisme énergétique musculaire et les caractéristiques musculaires déterminant la qualité organoleptique de la viande (Hocquette et al 1998a).

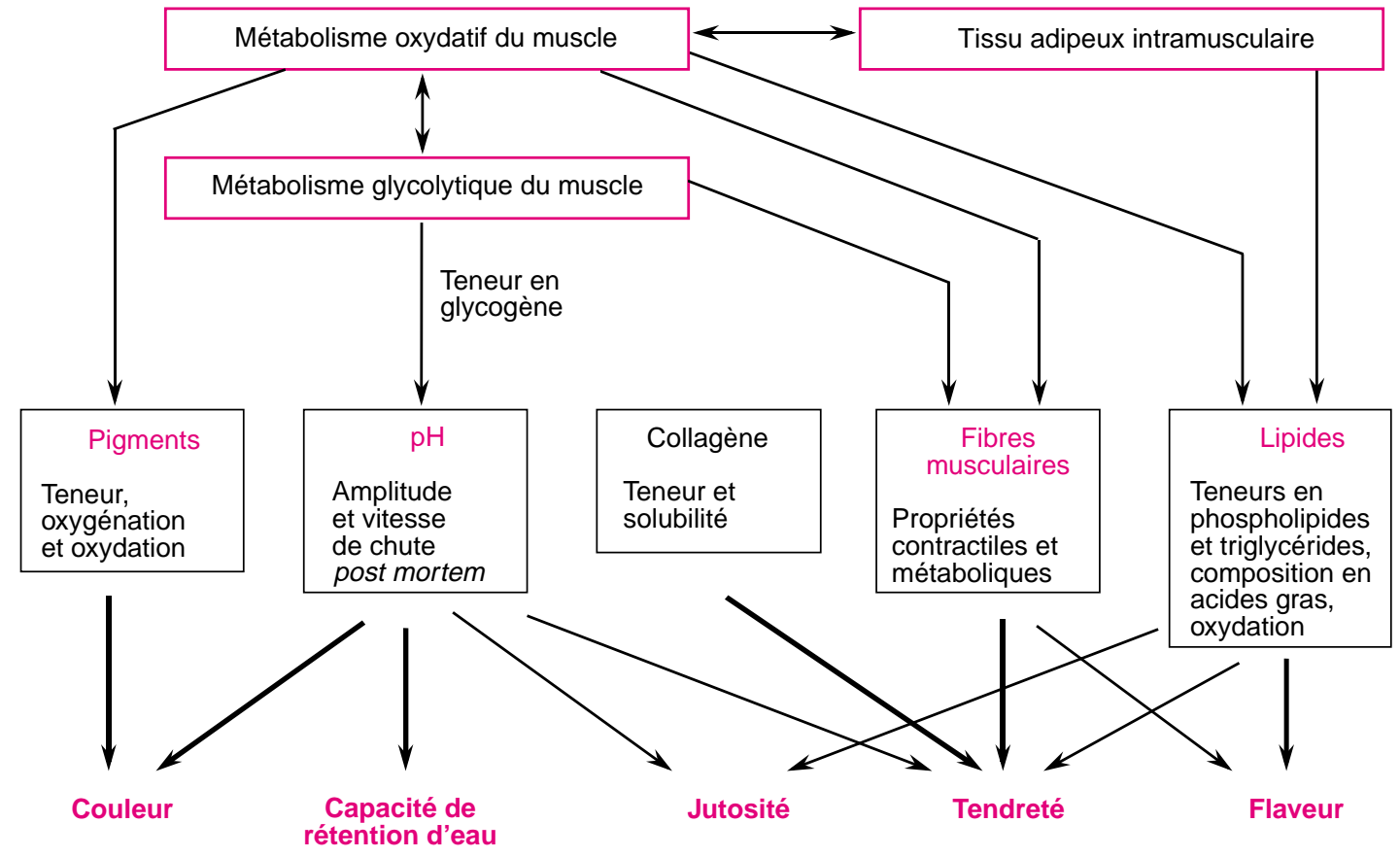


(figure 6). D'une façon générale, les muscles oxydatifs ont une teneur plus élevée en pigments (myoglobine) et donnent une viande plus rouge. La stabilité de la couleur dépend de l'état du pigment : la formation de metmyoglobine, par oxydation de la myoglobine, dépend de plusieurs facteurs dont l'évolution du $\mathrm{pH}$ post-mortem, la vitesse de diffusion de l'oxygène et la consommation d'oxygène par les mitochondries après l'abattage. Ainsi, la stabilité de la couleur de la viande est-elle meilleure chez le boeuf que chez l'agneau car les muscles du premier sont caractérisés par une faible consommation d'oxygène, contrairement à ceux du second (revue de Klont et al 1998).

La teneur en lipides du muscle joue un rôle important sur la jutosité et la flaveur de la viande et, dans une moindre mesure, sur sa tendreté (Touraille 1994 ; figure 6), mais, le goût de la viande varie peu au-delà d'une teneur en lipides de l'ordre de 3-4 \% (bovins : Touraille 1994, porcs : Lebret et al 1999). La maîtrise de la teneur en lipides s'avère particulièrement importante pour les espèces dont le contenu du muscle en lipides est faible (porc : 0,7-4 \% lapins : environ $1 \%$; revues de Wood et Warris 1992 et Fauconneau 1997) ou pour les muscles des bovins les plus glycolytiques et de valeur bouchère élevée (longi ssi mus thoraci s : 1,5 à $3 \%$ ). Toutefois, la flaveur de la viande fait intervenir de nombreux autres facteurs parmi lesquels la composition en acides gras des lipides, l'hydrolyse et l'oxydation des lipides après l'abattage (revues de Wood et Enser 1997 et Gandemer 1998) ainsi que l'oxydation des protéines et certains défauts d'odeur (odeurs sexuelles ou odeurs liées à l'alimentation; Touraille 1994). Enfin, la teneur en lipides peut avoir un effet favorable sur la tendreté de la viande : une corrélation génétique intrarace élevée $(+0,5)$ entre la tendreté et la teneur en lipides intramusculaires a été mise en évidence par des études réalisées aux USA (revue de Geay et Renand 1994).

J usqu'à présent, la plupart des effets du métabolisme énergétique musculaire sur la qualité de la viande ont été assimilés à l'influence du type de fibres sur la qualité. L'influence des propriétés des fibres musculaires sur la qualité de la viande n'est pas encore parfaitement claire (revue de Lebret $\mathbb{e}$ al 1999) et l'enjeu des recherches actuelles est de tenter d'apprécier les effets propres des caractéristiques contractiles (déterminant par exemple la vitesse de chute du $\mathrm{pH}$ post-mortem) et des caractéristiques métaboliques des fibres (teneur en glycogène, activités mitochondriales), ainsi que la contribution respective des fibres et des autres cellules musculaires (adipocytes) à la qualité (figure 6). II faudra notamment déterminer si la contribution du métabolisme des adipocytes intramusculaires à la teneur du muscle en lipides est importante et dissociable des caractéristiques propres des fibres musculaires (revue de Mourot et al 1999). A cet égard, les ruminants représentent un modèle intéressant car le substrat principal de la synthèse des acides gras longs dans les adipo- cytes intramusculaires est le glucose et non pas l'acétate comme dans les adipocytes de leurs autres tissus adipeux (Smith et Crouse 1984). II apparaît ainsi possible de limiter l'adiposité de la carcasse sans diminuer la teneur en lipides intramusculaires.

Le type de fibres peut aussi être associé à un métabolisme protéique particulier, mettant en jeu les activités des enzymes protéolytiques, indispensables à la maturation de la viande. La connaissance des interrelations entre type de fibres et métabolismes énergétique et protéique est donc indispensable pour maîtriser correctement in vi vo les effets des facteurs d'élevage et du type génétique sur les qualités de la viande.

\section{2 / Métabolisme énergétique du muscle au cours de la croissance foetale et postnatale}

D'importantes différences métaboliques entre muscles ont été observées après la naissance, selon l'activité et la fonction de ces muscles. Ainsi les muscles de la posture réalisant un effort continu sont à contraction lente et donc plus oxydatifs que les muscles à contraction rapide impliqués dans le mouvement dont certains sont très glycolytiques. Des variations d'activité métabolique, dont l'importance change au cours du développement, existent également au sein d'un même muscle et d'une extrémité à l'autre (Brandstetter et al 1997).

Chez les bovins, les différences métaboliques entre muscles apparaissent en fin de vie foetale (Gagnière et al 1999), alors que chez le porc, le lapin et le poulet, beaucoup moins matures à ce stade, elles n'apparaissent qu'après la naissance (Schmidt et Herpin 1997, revue de Hocquette et al 1998a). Différentes phases de l'ontogenèse du métabolisme oxydatif ont été mises en évidence au cours de la vie fœtale, pendant lesquelles les glucides contribuent pour plus de $75 \%$ au métabolisme oxydatif, quelle que soit l'espèce animale (revue de Girard et al 1979).

Au cours de la croissance postnatale chez le bovin, le métabolisme oxydatif diminue et le métabolisme glycolytique augmente. Cette évolution se poursuit jusqu'à l'âge de 12 mois chez le taurillon et 34 mois chez les femelles (vaches, génisses). Au-delà, l'évolution du métabolisme s'inverse et les muscles deviennent plus oxydatifs (revues de Hocquette et al 1996b et Geay et al 1997).

\section{3 / Contrôle génétique du métabolisme énergétique musculaire}

Jusqu'à présent, la sélection génétique a cherché à accroître le développement musculaire des animaux producteurs de viande, mais elle a induit, quelle que soit l'espèce animale, une augmentation du métabolisme glycolytique et une plus grande utilisation du glu- 
cose par le muscle, et une sensibilité accrue à I'insuline de ce tissu. Ainsi, par exemple, des lignées divergentes de moutons ou de bovins ont été sélectionnées en Australie sur la base du poids vif au sevrage ou de la vitesse de croissance. Les muscles des agneaux les plus lourds sont deux fois plus sensibles à l'insuline, captent davantage de glucose $(x 3,9)$ et utilisent moins d'oxygène $(-30 \%$; revue de Hocquette et al 1998a). De plus, la consommation d'oxygène et les intensités de synthèse et de dégradation protéiques dans le quartier arrière in vivo sont plus faibles chez les bovins sélectionnés pour une forte vitesse de croissance quand ils sont alimentés au-delà des besoins d'entretien (Oddy et al 1998).

Les progrès réalisés et les modifications du métabolisme musculaire ont été bien plus rapides chez les volailles du fait du faible intervalle de génération dans ces espèces. Cependant, des conséquences négatives de ce type de sélection sont apparues. Chez la dinde, I'orientation du métabolisme musculaire vers le type glycolytique est en effet associée à une moindre activité physique des animaux et à une moindre capillarisation des muscles. Ceci prédispose les muscles à l'acidose et à la fatigue et cette prédisposition est amplifiée par le stress dû au transport et au confinement dans les cages. Le résultat global est une accélération de la chute du $\mathrm{pH}$ des muscles après l'abattage et l'apparition de viande de type PSE (c'est-à-dire pâle, molle et exsudative) (revue de Sosnicki 1995).

De plus, la teneur du muscle en lipides variant dans le même sens que le développement des tissus adipeux (bovins : revue de Robelin et Casteilla 1990, porcs : revue de Lebret et al 1999), une sélection en faveur du développement musculaire et d'une diminution de l'adiposité de la carcasse a eu aussi pour résultat une diminution des teneurs en lipides intramusculaires. Ceci est actuellement un problème majeur chez le porc (revue de Wood et Warriss 1992) et des recherches sont actuellement conduites pour déterminer les mécanismes biologiques susceptibles de maintenir ou d'accroître le taux de lipides intramusculaires tout en réduisant l'adiposité de la carcasse (revue de Mourot et al 1999). C'est aussi pour répondre à cette interrogation que les consequences d'une sélection divergente des bovins sur la croissance musculaire font actuellement l'objet d'études pluridisciplinaires à I'INRA (Renand et al 1994).

A côté d'une sélection faisant appel à des caractères polygéniques, il est également possible de rechercher des génotypes particuliers caractérisés par l'influence d'un gène majeur. Ainsi, par exemple, la découverte récente d'un gène majeur récessif (imf) régissant la teneur en lipides intramusculaires chez le porc Meishan ouvre des perspectives de création de lignées homozygotes imf/imf dans un proche avenir ( $J$ anss $\notin$ al 1997).

Nous nous limiterons toutefois ici à l'exemple plus étudié des bovins culards. Ces animaux sont porteurs d'une mutation sur le gène de la myostatine, qui est un facteur inhi- bant la croissance musculaire (revue de Grobet et al 1998). Les conséquences de cette mutation proviennent de mécanismes biologiques pour l'essentiel inconnus. Les conséquences les plus évidentes sont une hypertrophie musculaire (de 7 à $40 \%$ selon les muscles), en raison d'un nombre plus élevé de fibres musculaires, et un développement moindre de la masse adipeuse $(-50 \%$ ) (revue de Clinquart et al 1998), en raison d'une hypotrophie relative des adipocytes (Hocquette et al 1999). Ces caractéristiques sont associées à des particularités endocriniennes (faible insulinémie, taux élevé de GH) favorables au dépôt de protéines et défavorables aux dépôts de lipides (Clinquart et al 1998, Hocquette et al 1999). De plus, le métabolisme energétique du muscle est plus glycolytique et/ou moins oxydatif chez les bovins culards, en accord avec une proportion plus élevée de fibres IIB et une proportion plus faible de fibres de type IIA. Le muscle du bovin culard tend également à être plus sensible à l'insuline et ce d'autant plus qu'il est hypertrophié. Par ailleurs, la vitesse de la glycolyse après abattage est plus élevée conduisant à une chute rapide du pH post-mortem. Cependant, le bovin culard étant plus sensible au stress, ses réserves musculaires en glycogène peuvent être insuffisantes, ce qui peut conduire à une viande à coupe sombre en raison d'un $\mathrm{pH}$ ultime trop élevé (revue de Hocquette et al 1998a). De plus, les teneurs intramusculaires en myoglobine et en lipides sont respectivement 1,4 et 2 à 3 fois plus faibles chez le culard que chez le bovin normal, ce qui se traduit par une viande plus pâle avec moins de goût (Clinquart et al 1998). Le bovin culard peut donc être considéré comme un type extrême qui peut permettre d'apprécier les conséquences, positives et, surtout, négatives, d'une sélection uniquement sur les performances de croissance sans critères de qualité.

\section{4 / Contrôle nutritionnel du métabolisme énergétique musculaire}

D'une façon générale, l'augmentation de la quantité d'énergie métabolisable ingérée s'accompagne d'un accroissement des dépôts de protéines et de lipides dans la carcasse des animaux. Toutefois, la consommation d'oxygène par le muscle n'augmente pas de facon systématique avec le niveau alimentaire, bien qu'il y ait des changements quantitatifs et qualitatifs dans les concentrations artérielles des différents nutriments énergétiques.

Lorsque I'on impose une période de sousalimentation aux animaux, les concentrations circulantes des AGNE et des corps cétoniques augmentent en raison de la mobilisation des réserves adipeuses et d'une cétogenèse hépatique accrue. La contribution des lipides au metabolisme énergétique musculaire est alors plus importante et le glucose préférentiellement recyclé sous forme de lactate (Boisclair et al 1993). Le jeûne ou la sous-alimentation sont également associés à des modifications hormonales importantes (faible

\author{
Augmenter les \\ apports alimen- \\ taires d'énergie \\ favorise les dépôts \\ de protéines, de \\ glycogène \\ et de lipides intra- \\ musculaires, mais \\ a ussi l'adiposité \\ globale de la car- \\ casse.
}


insulinémie) qui affectent les activités d'enzymes clés du métabolisme, notamment dans le tissu adipeux (revue de Faulconnier et al 1999). Un rationnement énergétique conduit à une diminution des dépôts adipeux par rapport à des animaux alimentés à volonté, ce qui induit une augmentation de la proportion de muscle. Celle des lipides intramusculaires diminue comme l'adiposité globale de la carcasse chez le porc (revue de Lebret et al 1999).

Chez les bovins en croissance élevés en système extensif, une période de sous-alimentation pendant la période hivernale est suivie d'une période de réalimentation au printemps, induisant une croissance compensatrice qui permet aux animaux de rattraper leur retard de croissance. La période de sousnutrition est caractérisée par des modifications des taux circulants d'hormones et de métabolites et un métabolisme musculaire plus oxydatif, ces changements étant réversibles pendant la période de réalimentation (revues de Micol et Picard 1997 et Hocquette et al 1998a).

De nombreuses recherches, conduites essentiellement chez les rongeurs de laboratoire, ont montré que certains nutriments énergétiques (acides gras, glucose) sont capables, par eux-mêmes, de modifier l'expression de gènes clés du métabolisme. Les nutriments lipidiques ou glucidiques affectent ainsi la répartition de l'énergie entre les différents compartiments corporels, modifiant ainsi les apports énergétiques au muscle à la fois sur le plan quantitatif et qualitatif (revue de Hocquette et al 1998a).

\section{5 / Contrôle hormonal du métabolisme énergétique musculaire}

\section{a / Insuline}

Parmi les facteurs hormonaux contrôlant le métabolisme énergétique musculaire, l'insuline est probablement le plus important. En effet, l'insuline modifie l'approvisionnement du muscle en nutriments par un effet direct de vasodilatation qui augmente le flux sanguin à travers les tissus, notamment musculaires, par une diminution de la néoglucogénèse dans le foie et de la lipolyse dans les tissus adipeux et par une augmentation du captage du glucose et des acides aminés par les tissus musculaires. Dans le muscle, l'insuline stimule le métabolisme du glucose en augmentant son captage par ce tissu, son oxydation, son recyclage en lactate et son stockage sous forme de glycogène. L'insuline augmente aussi le captage par le muscle d'autres nutriments tels que l'acétate. Enfin, elle joue un rôle majeur dans le métabolisme des lipides en dirigeant les acides gras à chaîne longue vers le dépôt de triglycérides plutôt que vers l'oxydation dans les muscles (revue de Hocquette et al 1996b et 1998a).

Une croissance rapide des tissus maigres aux dépens des tissus adipeux est générale- ment associée à une sensibilité accrue des muscles à l'insuline (revues de Hocquette et al 1996b et 1998a). Au contraire, les situations de résistance à l'insuline sont plutôt associées à une augmentation de l'insulinémie basale (revue de Bauchart et al 1996) et à une adiposité plus élevée de la carcasse. Chez le veau de boucherie ou les monogastriques, le développement de la résistance à l'insuline peut être en rapport avec une augmentation de l'âge des animaux (revue de Bauchart et al 1996) ou encore avec un excès de lipides ou de glucides d'origine alimentaire. Différents mécanismes faisant intervenir la fréquence des repas, la vitesse d'absorption intestinale du glucose ou l'importance du caractère saturé des lipides alimentaires ont été suggérés à partir de recherches essentiellement conduites chez le rat (revue de Hocquette et al 1998a). Au niveau moléculaire, les facteurs impliqués dans la réponse à l'insuline (revue de Simon et al 1995) et/ou les spécificités des transporteurs du glucose (Abe et al 1998) pourraient expliquer les différences de sensibilité des tissus à l'insuline.

\section{b / Hormone de croissance}

L'administration d'hormone de croissance exogène augmente le gain de poids, diminue le dépôt de lipides dans les tissus adipeux et accroît l'efficacité alimentaire, mais ces effets sont généralement plus faibles chez les ruminants que chez le porc (revue de Kopchick et Cioffi 1991). Bien que l'hormone de croissance augmente les intensités de synthèse et de dégradation des protéines dans le muscle, aucune différence significative dans les dépenses énergétiques du muscle n'a pu être mesurée. Dans le tissu adipeux, les effets de I'hormone de croissance sont généralement opposés à ceux de l'insuline. Ainsi, en inhibant la lipogénèse et en augmentant la lipolyse, la nature des substrats énergétiques mis à la disposition du muscle est modifiée en raison d'une augmentation probable des apports d'AGNE au muscle (revue de Vernon et Flint 1989 et Hocquette et al 1998a). Le taux de captage du glucose par le muscle reste inchangé par l'hormone de croissance, mais le recyclage du glucose en lactate est accru (Dunshea et al 1995, Wray-Cahen et al 1995).

Les modifications du métabolisme par l'hormone de croissance peuvent avoir des conséquences sur les caractéristiques musculaires impliquées dans la qualite de la viande, comme, par exemple, un métabolisme plus glycolytique de certains muscles et une réduction du taux de lipides intramusculaires (Lefaucheur et al 1992). Toutefois, la teneur en glycogène du muscle et le $\mathrm{pH}$ ultime de la viande ne sont généralement pas modifiés chez les animaux traités par l'hormone de croissance (Allen et E nright 1989, Lefaucheur et al 1992, revue de Lebret et al 1999).

\section{c / Autres hormones}

Les hormones thyroïdiennes augmentent la biosynthèse (c'est-à-dire la multiplication) et l'activité des mitochondries, l'oxydation des lipides et les dépenses énergétiques en raison 
d'un accroissement du turnover protéique et des transports ioniques (revue de Hocquette et al 1998a). Les hormones thyroïdiennes orientent donc le métabolisme musculaire vers le type oxydatif, mais, dans le même temps, elles stimulent la synthèse des chaînes lourdes des myosines rapides (revue de Cassar-Malek et al 1998).

Les ß2-agonistes augmentent le dépôt et la synthèse des protéines tout en diminuant la dégradation des protéines et le dépôt de lipides (revue de Sillence 1996). Ces modifications du métabolisme sont probablement associées à une augmentation des besoins en oxygène du muscle, à une contribution plus importante des AGNE au métabolisme musculaire et à un recyclage accru du glucose en lactate par le muscle (Eisemann ef al 1988) Elles peuvent avoir des conséquences sur les caractéristiques musculaires impliquées dans la qualité de la viande, comme, par exemple, une réduction du taux de lipides intramuscu laires (revues de Wood et Warris 1992 et Geay et Renand 1994). La modification la plus importante est une forte réduction de la tendreté de la viande en raison, très probablement, d'une faible dégradation des protéines au cours de sa maturation (Geay et Renand 1994). Cette dernière peut être mise en relation avec une réduction de l'activité des enzymes protéolytiques (calpaïnes) et un accroissement de l'activité de leur inhibiteur (calpastatine), la réduction de la teneur en lipides du muscle pouvant également contribuer à la dureté de la viande.

\section{Conclusion}

Les relations entre le métabolisme énergétique musculaire, l'efficacité de la croissance et la qualité de la viande sont complexes et encore partiellement méconnues. En particulier, on connaît encore insuffisamment les caractéristiques métaboliques prioritairement favorables à la qualité de la viande, selon l'espèce animale (volailles, porc, lapin, veau, gros bovins) ou le type de produits (viande cuite, produits crus). Toutefois, quelques grandes tendances peuvent être dégagées des résultats actuellement disponibles.

L'orientation du métabolisme musculaire vers le type glycolytique conduit à une meilleure utilisation du glucose comme source d'énergie, à une plus grande sensibilité du muscle à l'insuline et est généralement associée à un développement accru du tissu musculaire, à une réduction des dépenses énergétiques par unité de gain de muscle et à une augmentation de la teneur du muscle en glycogène. Cela se traduit, chez le bovin, par une plus grande vitesse de maturation de la viande et donc par une meilleure tendreté. Cela peut aussi entraîner une diminution de la couleur et de la flaveur. Mais on manque d'informations d'une part sur la partition du glucose entre les voies de la lipogenèse, de la glycolyse, de l'oxydation et de la synthèse de glycogène, et, d'autre part, sur le turnover des lipides entre les fibres musculaires et les adipocytes intramusculaires.

L'amélioration de la croissance musculaire par la sélection génétique conduit à des animaux ayant un métabolisme musculaire plus glycolytique et moins oxydatif. La teneur en lipides intramusculaires est alors plus faible. La qualité de la viande en termes de couleur, de jutosité et de flaveur est généralement diminuée.

Une augmentation des apports énergétiques alimentaires, associée à un taux circulant d'insuline plus élevé, favorise les dépôts de protéines, de glycogène et de lipides. Elle se traduit bien, chez le bovin et le porc, par une amélioration de la croissance musculaire, une proportion plus élevée de fibres glycolytiques, et permet l'accroissement de la teneur en lipides intramusculaires. Toutefois, des apports énergétiques excessifs ou un taux circulant d'insuline trop élevé induisent une résistance du muscle à l'insuline, ce qui favorise le développement du tissu adipeux de la carcasse aux dépens de celui du muscle.

L'activité physique des animaux associée à des conditions climatiques variables peut théoriquement changer les qualités organoleptiques des viandes en modifiant les caractéristiques du métabolisme musculaire. C'est pourquoi, dans le cadre de l'évaluation objective de l'impact des nouveaux systèmes d'élevage (productions dites alternatives) sur les performances et la qualité des produits, ces facteurs de variation du métabolisme énergétique musculaire font l'objet d'études en cours.

\section{Références}

Abe $\mathrm{H}$. Kawakita $Y$., Miyashige T., Moritmatsu M., Saito M. 1998. Comparison of amino acid sequence of the C terminal domain of insulin-responsive glucose transpor ter (GLUT4) in livestock species. J. Vet. Med. Sci., 60, 769 771.

Agabriel J ., Bony J., Micol D., 1998. Le bison d'Amérique. Elevage, production et qualité de la viande. INRA, Paris, $106 \mathrm{p}$.

Allen P., Enright W.J ., 1989. Effects of administration of somatotropin on meat quality in ruminants: a review. In K. Sejrsen, A. Neimann-Sorensen (eds.), Use of somato- tropin in livestock production, 201-209. Elsevier Applied Science, London and New-York.

Aoki Y., Yamada A., Nakanishi N., Yamazaki T., Harashima N., Nishida T., 1995. Effects of grazing on plasma concentrations of insulin, glucose, non-esterified fatty acids and triglycerides in reared beef steers. Bull. Natl. Grassl. Res. Inst., 51, 50-56.

Bauchart D., Ortigues I., Hocquette J.F., Gruffat D., Durand D., 1996. Energy and fat metabolism of the liver, the digestive tract and muscles: transport, processing, energy consumption, fixation by tissues. In : The French 
Federation of Veal Producers (ed), Veal, Perspectives to the year 2000, Proc. International Symposium, Le Mans, France, 255-290. Presse de J ouve, Le Mans, France.

Berthon D., Herpin P., Bertin R., Demarco F., Le Dividich J. 1996. Metabolic changes associated with sustained 48hr shivering thermogenesis in the newborn pig. Comp. Biochem. Physiol., 114(B), 327-335.

Boisclair Y.R., Bell A.W., Dunshea F.R., Harkins M., Bauman D.E., 1993. Evaluation of the arteriovenous difference technique to simultaneously estimate protein synthesis and degradation in the hindlimb of fed and chronically underfed steers. J. Nutr., 123, 1076-1088.

Boss P. Muzzin, Giacobino J .P., 1998. The uncoupling proteins, a review. Eur. J. Endocrinol., 139, 1-9.

Brandstetter A.M., Picard B., Geay Y., 1997. Regional variations of muscle fibre characteristics in $\mathrm{m}$. semiten dinosus of growing cattle. J. Muscle Res. Cell Motility, 18, 57-62.

Cassar-Malek I., Listrat A., Picard B., 1998. Contrôle hormonal des caractéristiques des fibres musculaires après la naissance. INRA Prod. Anim., 11, 365-377.

Clausen T., 1986. Regulation of active $\mathrm{Na}+\mathrm{K}+$ transport in skeletal muscle. Physiol. Rev., 66, 542-580.

Clinquart A., Hornick J.L., Van Eenaeme C., Istasse L., 1998. Influence du caractère culard sur la production et la qualité de la viande des bovins Blanc Bleu Belge. INRA Prod. Anim., 11, 285-297.

Damon M., Vincent A., Lombardi A., Herpin P., 2000. First evidence of uncoupling protein-2 and -3 gene expression in piglet skeletal muscle and adipose tissue. Gene, 246, 133-141.

Duchamp C., Barré, H., 1993. Skeletal muscle as the major site of nonshivering thermogenesis in cold-acclimated ducklings. Am. J. Physiol., 265, R 1076-1083.

Duchamp C., Cohen-Adad F., Rouanet J .L., Barré H., 1992 Histochemical arguments for muscular non-shivering thermogenesis in muscovy ducklings. J. Physiol., 457, 2745.

Dunshea F.R., Boisclair Y.R., Bauman D.E., Bell A.W., 1995. Effects of bovine somatotropin and insulin on whole-body and hindlimb glucose metabolism in growing steers. J. Anim. Sci., 73, 2263-2271.

Eisemann J.H., Huntington, G.B., Ferrell, C.L., 1988. Effects of dietary clenbuterol on metabolism of the hindquarters in steers. J. Anim. Sci., 66, 342-353.

Elia M., 1995. General integration and regulation of metabolism at the organ level. Proc. Nutr. Soc., 54, 213-232.

Essen-Gustavsson B., Lundstrom K., Larsson G., Lindholm A., Nordin A-C., Hasson I., Tornber G.E., 1988. The effect during growth of moderate exercise on muscle metabolic characteristics in vivo and relation to meat quality and sensory properties. Inter. Cong. Meat Sci. Tech., 34, 27.

Faergeman N.J., Knudsen J., 1997. Role of long-chain fatty acyl-coA esters in the regulation of metabolism and in cell signalling, Biochem. J., 323, 1-12.

Fauconneau G., 1997. Aspects nutrtionnels de la consommation des viandes. Perspectives d'avenir. Viandes Prod. Carnés, 18, 79-85.
Faulconnier $Y_{\text {., }}$ Bonnet $M_{\text {., Bocquier }} F_{\text {., Leroux }} C_{\text {., }}$ Hocquette, J.F., Martin P., Chilliard Y., 1999. Effet du niveau alimentaire et de la photopériode sur l'expression de gènes contrôlant le métabolisme tissulaire chez le ruminant. INRA Prod. Anim., 12, 287-300.

Freake H.C., 1998. Uncoupling proteins: beyond brown adipose tissue. Nutr. Rev. 56, 185-189.

Gagnière H, Picard B., Jurie C., Geay Y., 1999 Comparison of fœtal metabolic differentiation in three cattle muscles. Reprod. Nutr. Dev., 39, 105-112.

Gandemer G., 1998. Lipids and meat quality, lipolysis, oxidation and flavour. Proc. 44th International Congress of Meat Science and Technology, Spain, 106-119.

Geay Y., Renand, G., 1994. .Importance de la variabilité génétique et du mode d'élevage des bovins sur les carac téristiques musculaires et les qualités organoleptiques de leurs viandes. Renc. Rech. Ruminants, 1, 177-182.

Geay Y., Picard B., Renand G., 1997. Variability in muscle fibre types during muscle development; effect of some hormones, muscle type and genotype. SatelliteSymposium I of the 48th Annual Meeting of the European Association for Animal Production «Beef Production with special respect to beef quality». 23 August 1997 Vienna (Austria).

Girard J., Pintado E., Ferré P., 1979. Fuel metabolism in the mammalian fetus. Ann. Biol. Anim. Biochim. Biophys., 19, 181-197.

Grobet L., Royo L., Poncelet D., Pirottin D., Brouwers B., Riquet J., Schoeberlein A., Michaux C., Masabanda J., Fries R., Dunner S., Ménissier F., Zanotti M., Hanset R., Georges M., 1998. Positional candidate cloning of the myostatin gene in cattle and identification of a series of mutations causing the double muscling phenotype. In : J.W. Blum, T. Elsasser and P. Guilloteau (eds), Proc Symposium on Growth in Ruminants: Basic Aspects Theory and Practice for the Future, 70-73. University of Berne (Switzerland), 20-22 août 1998.

Harman N.G. 1991. Energy metabolism in rested, exercised and over-fed sheep. PhD Thesis, Murdoch University, Western Australia.

Hedden M.P., Buse M.G., 1982. Effects of glucose, pyruvate, lactate, and amino acids on muscle protein synthesis. Am. J. Physiol., 24, E 184-E 192.

Henriksson J., 1995. Muscle fuel selection: effect of exercise and training. Proc. Nutr. Soc., 54, 125-138.

Herpin P., Lefaucheur L., 1992. Adaptative changes in oxidative metabolism in skeletal muscle of cold-acclimated piglets. J. Therm. Biol., 17, 277-285.

Herpin P., McBride B.W., Bayley H.S., 1987. Effect of cold exposure on energy metabolism in the young pig. Can. J. Physiol. Pharmacol., 65, 236-245.

Hocquette J.F., Bauchart D., 1999. Intestinal absorption, blood transport and hepatic and muscle metabolism of fatty acids in preruminant and ruminant animals. Reprod. Nutr. Dev., 39, 27-48.

Hocquette J .F., Balage M., Ferré P., 1996a. Facilitative glucose transporters in ruminants. Proc. Nutr. Soc., 55, 221 236

Hocquette J.F., Picard B., Fernandez X., 1996b. Le métabolisme énergétique musculaire au cours de la croissance et après abattage de l'animal. Viandes Prod. Carnés, $17,217-230$. 
Hocquette J .F., Castiglia-Delavaud C., Graulet B., Ferré P. Picard B., Vermorel M., 1997. Weaning marginally affects glucose transporter (GLUT4) expression in calf muscles and adipose tissues. Br. J. Nutr., 78, 251-271.

Hocquette J .F., Ortigues-Marty I., Pethick D.W., Herpin P. Fernandez X 1998a. Nutritional and hormonal regulation of energy metabolism in skeletal muscles of meatproducing animals. Livest. Prod. Sci., 56, 115-143.

Hocquette J.F., Ortigues-Marty I., Vermorel M., 1998b. Nutritional regulation of energy metabolism in growing ruminants. In : J.W. Blum, T. Elsasser and P. Guilloteau (eds), Proc. Symposium on Growth in Ruminants: Basic Aspects, Theory and Practice for the Future, 76-85. University of Berne (Switzerland), 20-22 août 1998.

Hocquette J .F., Bas P., Bauchart D., Vermorel M., Geay Y. 1999. Fat partitioning and biochemical characteristics of fatty tissues in relation to plasma metabolites and hormones in normal and double-muscled young growing bulls. Comp. Biochem. Physiol., A, 122, 127-138. Erratum, 1999. Comp. Biochem. Physiol., A, 123, 311-312.

Hoppeler H., 1986. Exercise-induced ultrastructura changes in skeletal muscle. Int. J. Sports Med., 7, 187-204.

Janss L.L., van Arendonk J.A., Brascamp E.W. 1997 Bayesian statistical analyses for presence of single genes affecting meat quality traits in a crossed pig population. Genetics, 145, 395-408.

eukendrup A.E., Saris W.H.M., Wagenmakers A.J.M 1998. Fat metabolism during exercise: a review. Int. I. Sports Med, 19, 231-244.

J urie C., Picard B., Geay Y., 1998. Influences of the method of housing bulls on their body composition and muscle fiber types. Meat Sci., 50, 457-469.

Klont R.E., Eikelenboom G., Brocks L., 1998. Muscle fiber type and meat quality. Proc 44th International Congress of Meat Science and Technology, Spain, 98-105.

Kopchick J J., Cioffi J.A., 1991. Exogenous and endogenous effects of growth hormone in animals. Livest. Prod. Sci., 27, 61-75.

Lebret B., Lefaucheur L., Mourot J ., 1999. La qualité de la viande porc. Influence des facteurs d'élevage non génétiques sur les caractéristiques du tissu musculaire. INRA Prod. Anim., 12, 11-28.

Lefaucheur L., Le Dividich J ., Mourot I ., Monin G., Ecolan P., Krauss D., 1991. Influence of environmental tempera ture on growth, muscle and adipose tissue metabolism and meat quality in swine. J. Anim. Sci., 69, 2844-2854.

Lefaucheur L., Missohou A., Ecolan P., Monin G. Bonneau M., 1992. Performance, plasma hormones, histochemical and biochemical muscle traits, and meat quality of pigs administred exogenous somatotropin between 30 or 60 kilograms and 100 kilograms body weight. J. Anim. Sci., 70, 3401-3411.

Lister D., Spencer G.S.G., 1983. Energy substrate provision in vitro and the changes in muscle $\mathrm{pH}$ post mortem. Meat Sci., 8, 41-51.

Lobley G.E., 1991. Organ and tissue metabolism: present status and future trends. In : Wenk $C$. and Boessinger $M$. (eds), Energy Metabolism of Farm Animals, 80-87. Institut für Nutztierwissenschraften, Zürich.

Lobley G.E., 1994. Nutritional and endocrine regulation of energy metabolism. In : J.F. Aguilera (ed), Energy Metabolism of Farm Animals, 139-149. Consejo Superio de Investigaciones Cientificas, Granada.
Lossec G., Lebreton Y., Hulin J.C., Fillaut M., Herpin P., 1998. Age-related changes in oxygen and nutrient uptake by hindquarters in newborn pigs during cold-induced shivering. Exp. Physiol., 83, 793-807.

MacLennan P.A., Rennie M.J., 1989. Effects of ischaemia, blood loss and reperfusion on rat muscle protein synthesis, metabolite concentrations and polyribosome profiles in vivo. Biochem. J., 260, 195-200.

Micol D., Picard B., 1997. Production de viande bovine à 'herbe et qualité. Fourrages, 152, 417-428.

Mourot J., Kouba M., Salvatori G., 1999. Facteurs de variation de la lipogenèse dans les adipocytes et les tissus adipeux chez le porc. INRA Prod. Anim., 12, 311-318.

Newman J .M.B., Dora K.A., Rattigan S., Edwards S.J ., Colquhoun E.Q., Clark M.G., 1996. Norepinephrine and serotonin vasoconstriction in rat hindlimb control different vascular flow routes. Am. J. Physiol., 270, E689-699.

Oddy V.H., Herd R.M., McDonagh M.B., Woodgate R. Quinn C.A., Zirker K., 1998. Effect of divergent selection for yearling growth rate on protein metabolism in hindlimb muscle and whole body of Angus cattle. Livest. Prod. Sci., 56, 225-231.

Ortigues I., 1991. Adapatation du métabolisme énergétique des ruminants à la sous-alimentation. Quantification au niveau de l'animal entier et de tissus corporels. Reprod. Nutr. Dev., 31, 593-616.

Ortigues I., Doreau M., 1995. Responses of the splanchnic tissues of ruminants to changes in intake: absorption of digestion and products, tissue mass, metabolic activity and implications to whole animal energy metabolism. Ann. Zootech., 44, 321-346.

Ortigues I., Vermorel M., 1996. Adaptation of whole animal energy metabolism to undernutrition in ewes: influence of time and posture. Anim. Sci., 63, 413-422.

Ortigues I., Visseiche A.L., 1995. Whole body fuel selection in ruminants: nutrient supply and utilization by major tissues. Proc. Nutr. Soc., 54, 235-251.

Pethick D.W. 1984. Energy metabolism of skeletal muscle. In : Gawthorne J .M., Baker S.K., Mackintosh J .B. and Purser D.B. (eds), Ruminant Physiology. Concepts and Consequences, 277-287. University of Western Australia.

Pethick D.W., Dunshea F.R., 1993. Fat metabolism and turnover In: Forbes J.M. and France J. (eds) Quantitative aspects of Ruminants Digestion and Metabolism, 291-311. CAB International.

Pethick D.W., Rowe J.B., 1996. The effect of nutrition and exercise on carcass parameters and the level of glycogen in skeletal muscle of Merino sheep. Aust. J. Agric. Res., 47, 525-37.

Renand G., Berge P., Picard B., Robelin I ., Geay Y., Krauss D., Ménissier F., 1994. Genetic parameters of beef production and meat quality traits of young Charolais bulls progeny of divergently selected sires. Proc. 5th world congress in genetics applied to livestock production, Vol 19, 446-449, Guelph Canada.

Ricquier D., Bouillaud F., 2000. The uncoupling protein homologues: UCP1, UCP2, UCP3, StUCP and AtUCP. Biochem. J., 345, 161-179.

Robelin J ., Casteilla L., 1990. Différenciation, croissance et développement du tissu adipeux. INRA Prod. Anim., 3, 243-252.

INRA Productions Ani males, jui llet 2000 
Rolfe D.F.S., Brand M.D., 1997. The physiological significance of mitochondrial proton leak in animal cells and tissues. Biosci. Reports, 17, 9-16.

Rolfe D.F., Brown G.C., 1997. Cellular energy utilization and molecular origin of standard metabolic rate in mammals. Physiol. Rev., 77, 731-58.

Sahlin K., 1986. Metabolic changes limiting muscle performance. In: Saltin B. (ed), Biochemistry of exercise, 323-343. International Series on Sport Sciences, vol. 16. Human Kinetics Publ.: Champaign, Illinois.

Schmidt I., Herpin P., 1997. Postnatal changes in mitochondrial protein mass and respiration in skeletal muscle from the newborn pig. Comp. Biochem. Physiol., 118B, 639-647.

Schmidt I., Herpin P., 1998. Carnitine palmitoyltransferase I activity and its regulation by malonyl-COA are modulated by age and cold exposure in skeletal muscle mitochondria from newborn pigs. J. Nutr., 128, 886-893.

Sellier P., Monin G., 1994. Genetics of pig meat quality: a review. J. Muscle Foods, 5, 187-219.

Sidossis L.S., Wolfe R.R., 1996. Glucose and insulin-induced inhibition of fatty acid oxidation: the glucose fatty acid cycle reversed. Am. J. Physiol., 33, E 733-738.

Sillence M.N., 1996. Evaluation of new technologies for the improvement of nitrogen utilization in ruminants. In Kornegay E.T. (ed), Nutrient management of food animals to enhance and protect the environment, 105-133. Lewis Publ. Boca Raton, FL.

Simon J., 1995. Insulin-glucagon in broilers. OECD Workshop. Growth and Quality in Broiler Production. Celle, Germany. Sonderheft 1 Archiv für Geflügelkunde, 14-17
Smith S.B., Crouse J.D., 1984. Relative contributions of acetate, lactate and glucose to lipogenesis in bovine intramuscular and subcutaneous adipose tissue. I. Nutr. $114,792-800$.

Sosnicki A.A., 1995. The domestic turkey: a model of the impact of selection and production practices on meat quality. In : Ouali A., Demeyer D. and Smulders F.J.M. (eds), Expression of tissue proteinases and regulation of protein degradation as related to meat quality, 363-377. ECCEAMST, Utrecht, The Netherlands.

Touraille C., 1994. Incidence des caractéristiques musculaires sur les qualités organoleptiques des viandes. Renc Rech. Ruminants, 1, 169-176.

Vernon R.G., Flint D.J ., 1989. Role of growth hormone in the regulation of adipocyte growth and function In Heap R.B., Prosser C.G. and Lamming G.E. (eds), Biotechnology in growth regulation, 57-71. Butterworths, London.

Wood J.D., Enser M., 1997. Factors influencing fatty acids in meat and the role of antioxidants in improving meat quality. Br. J. Nutr., Suppl. 1, S49-S60.

Wood J.D., Warris P.D., 1992. The influence of the manipulation of carcass composition on meat quality. In Buttery P.J ., Boorman K.N. and Lindsay D.B. (eds), The control of fat and lean deposition, 331-334. Butterworths Heinmann Ltd, Oxford.

Wray-Cahen D., Bell A.W., Boyd R.D., Ross D.A., Bauman D.E., Krick B.J ., Harrell R.J ., 1995. Nutrient uptake by the hindlimb of growing pigs treated with porcine somatotropin and insulin. J. Nutr., 125, 125-135.

Young V., Yu Y.M., Fukagawa N.K., 1992. Energy and protein turnover. In : Kinney J.M. and Tucker H.N. (eds), Energy metabolism: Tissue determinants and cellular corollaries, 439-466. Raven Press Ltd, New York.

\section{Abstract}

Energy metabolism in skeletal muscle of meat-producing animals.

In meat-producing animals, skeletal muscle is a tissue of major economic importance. Its main physiological functions are thermogenesis, posture and physical activity. Each of these and muscle growth present specific energy requirements, which may be responsible for competitions between the different metabolic pathways of the utilisation of energy-yielding nutrients. These metabolic regulations modify the efficiencies of ATP production and utilisation, as well as some muscle characteristics which are essential for meat quality. For example, a more glycolytic muscle metabolism is associated with a better utilisation of glucose, a higher sensitivity of muscle to insulin, an increased muscle development, a reduction in its energy expenditure and an increase in its glycogen content. Improvement of muscle growth through genetic selection induces a less oxidative muscle metabolism associated with a lower intramuscular lipid content. A rise in the supply of energy-yielding nutrients is in favour of protein, glyco- gen and intramuscular lipid deposition. Nevertheless, an excess in energy may be responsible for an enhanced resistance of muscle to insulin which then favours carcass adiposity. The turnover and the partition of nutrients among the intramuscular anabolic (lipogenesis, glycogenesis) and catabolic (glycolysis, lipolysis, oxidation) pathways remain to be investigated. Physical activity of animals and cold adaptation modify muscle characteristics in favour of oxidative metabolism. The issue which remains to be addressed today is to determine whether the optimisation of the efficiency of ATP production and utilisation is compatible with the improvement of meat quality, especially through its glycogen and intramuscular lipid contents.

HOCQUETTE J.-F., ORTIGUES-MARTY I., DAMON M., HERPIN P., GEAY Y., 2000. Métabolisme énergétique des muscles squelettiques chez les animaux producteurs de viande. INRA Prod. Anim., 13, 185-200. 